NASA

Technical Memorandum 102456

AIAA-90-0668
AVSCOM

Technical Report 89-C-015

\title{
Comparison of Two Droplet Sizing Systems in an Icing Wind Tunnel
}

J.R. Oldenburg

Lewis Research Center

Cleveland, Ohio

and

R.F. Ide

Propulsion Directorate

U.S. Army Aviation Research and Technology Activity-AVSCOM Lewis Research Center

Cleveland, Ohio

Prepared for the

28th Aerospace Sciences Meeting sponsored by the American Institute of Aeronautics and Astronautics Reno, Nevada, January 8-11, 1990

\section{N/SA}

(NASA-TM-102456) COMOADISOM OF TWO DROPLTT SILING SYSTFMS IN AN ILING WIND TUNNEL (NACA) $19 \mathrm{p}$

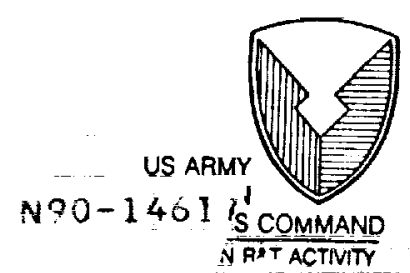




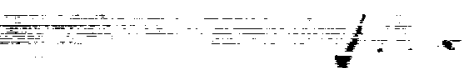
$\frac{3}{5=}$ 


\title{
COMPARISON OF TWO DROPLET SIZING SYSTEMS IN AN ICING WIND TUNNEL
}

\author{
John R. Oldenburg \\ National Aeronautics and Space Administration \\ Lewis Research Center \\ Cleveland, Ohio \\ Robert F. Ide \\ Propulsion Directorate \\ U.S. Amy Aviation Research and Technology Activity-AVSCOM \\ NASA Lewis Research Center \\ Cleveland, Ohio
}

\begin{abstract}
$\underline{\text { Abstract }}$
A comparison between the Phase Doppler Particle Analyzer and the combined measurements from Particle Measuring Systems' Forward Scattering Spectrometer Probe and the Optical Array Probe was conducted in an icing wind tunnel using NASA Icing Research Tunnel spray nozzles to produce the supercooled water droplet cloud. Clouds which had a range of volume median diameters from 10 to greater than 50 microns were used for the instrument comparisons. A comparison of the volume median diameter from the Phase Doppler Particle Analyzer and the Forward Scattering Spectrometer Probe indicated agreement up to 18 microns. A volume median diameter was calculated from combining the droplet distributions of the Optical Array Probe and the Forward Scattering Spectrometer Probe. A comparison of the combined volume median diameters and the Phase Doppler Particle Analyzer volume median diameters showed agreement up to 30 microns. The agreement deteriorated rapidly above 30 microns. Droplet distributions from the Phase Doppler Particle Analyzer, the Forward Scattering Spectrometer Probe, and Optical Array Probe are presented.
\end{abstract}

\section{Introduction}

The accretion of ice on aircraft components is very sensitive to the supercooled cloud droplet size distribution which, in icing research, is typically characterized by the volume median diameter (MVD). Therefore, it is important that instrumentation can accurately and reliably measure the droplet distribution. In the last two decades, laser based systems have been developed to provide a fast efficient means of obtaining the droplet distributions. In icing research, the Forward

Copyright (C) 1990 by the American Institute of Aeronautics and Astronautics, Inc. No copyright is asserted in the United States under Title 17, U.S. Code. The U.S. Government has a royalty-free license to exercise all rights under the copyright claimed herein for Governmental purposes. All other rights are reserved by the copyright owner.
Scattering Spectrometer Probe (FSSP) and Optical Array Probe (OAP), manufactured by Particle Measuring Systems, Inc. (PMS), are most commonly used.

Although the PMS probes are commonly used, they have important limitations. Their large physical dimensions prevent them from being used in many test facilities. Also, for clouds with MVDs greater than 20 microns both the FSSP and OAP are required to adequately characterize the cloud. This requires using a facility large enough to operate both probes simultaneously or repeating the test cloud with each probe individually. Because of these limitations, NASA Lewis Research Center is sponsoring the development of a new instrument for icing cloud measurements based on the Phase Doppler Particle Analyzer (PDPA) manufactured by Aerometrics, Inc. ${ }^{1}$ This development program strives to incorporate the large adjustable size range of the current PDPA into a rugged compact probe.

To improve the understanding of the PDPA and PMS probes a comparison test was conducted over a typical range of icing cloud conditions. The results of this test also will provide useful data for the development of a new droplet sizing instrument for supercooled cloud characterization.

\section{Apparatus and Procedure}

\section{Icing Tunnel}

The comparison test was conducted in the BFGoodrich Icing Wind Tunnel in Uniontown, Ohio. The tunnel had a test section which was 22 inches wide $x$ 44 inches high $\times 5$ feet long. The tunnel could supply air temperatures down to $-20^{\circ} \mathrm{F}$ and velocities up to 200 mph. ${ }^{2}$ The test section had a door on each side of the tunnel with heated windows measuring $12 \times 30$ inches which provided optical access for the PDPA. 


\section{Spray Nozzles}

NASA Icing Research Tunnel (IRT) Standard and Mod1 spray nozzles and BFGoodrich's equivalent spray nozzles were used to produce the icing cloud. The nozzle configuration is shown in figure 1 . The Standard and Mod1 nozzles are identical except for the water tube size. To limit droplet number densities, only four spray nozzles were used for most tests.

\section{Droplet Sizing Instruments}

The instruments used in the comparison were a Particle Measuring Systems Forward Scattering Spectrometer Probe Model FSSP-100 and Optical Array Probe Model OAP-200X, and an Aerometrics, Inc., Phase Doppler Particle Analyzer. The FSSP had a size range of 0.5 to 47 microns and the OAP had a size range of 15 to 310 microns. Each instrument had 15 equally sized bins. Because of the limited maximum droplet diameter measurable by the FSSP, the FSSP and OAP distributions were combined into one distribution for comparison with the PDPA. The PDPA had a size range which could be adjusted within limits defined by the optical configuration. The size range had 50 equally sized bins with a fixed ratio between the largest and smallest size bins of 35:1. The PDPA size range was defined during testing to best measure the droplet size distribution of each icing cloud.

Forward Scattering Spectrometer Probe (FSSP). The optical configuration of the FSSP is shown in figure 2. The FSSP established the size of a water droplet by measuring the intensity of light scattered into the collecting optics by a droplet traversing the focused region of the laser beam. The peak intensity of the scattered light increases with increasing droplet size. Droplets are sized one at a time and placed in one of 15 size bins. The FSSP had four size ranges. The largest range, 2 to 47 microns, was used for the comparison. For additional information on the operation of the FSSP refer to reference 3 .

Optical Array Probe (OAP). The optical configuration of the OAP is shown in figure 3. A laser beam is projected across the open space between two probe arms, magnified by a set of lenses, and projected onto a 24 element linear photodiode array. Droplets crossing the laser beam shadow one or more of the photodiode elements. The droplet size is determined by the number of photodiode elements shadowed, the element spacing, and the magnification factor of the droplet image. The Model OAP-200X has 15 size channels, the photodiode elements are spaced on 200 micron centers, and the magnification is $10 \mathrm{X}$ which defines a size range of 15 to 310 microns with nominal 20 micron bin width. Refer to reference 4 for additional information on the OAP.

Combined FSSP and OAP Distribution. Because the FSSP is limited to a maximum droplet size of 47 microns, it is necessary to combine the FSSP and OAP distribution to produce a complete characterization of the droplet size distribution which will be refer to as a PMS distribution. This PMS distribution is used to calculate a MVD for comparison to the MVD calculated from the PDPA droplet size distribution.

The PMS distribution was generated by excluding the first two size bins of the OAP and combining the size bins from each instrument which has been normalized by their respective sample volumes. The sample volume is the product of the sample area, measurement time, and air velocity. The first two size bins of the OAP were omitted because of the errors which occur in these bins. ${ }^{7}$ The counts in these bins are typically lower than the counts in the equivalent FSSP bins. The resultant PMS distribution has a size range from 2 to 310 microns with a small gap from 47 to 54 microns.

Phase Doppler Particle Analyzer (PDPA). The Phase Doppler Particle Analyzer 5,6 developed by Aerometrics, Inc. uses scattered light from droplets to make simultaneous droplet size and velocity measurements. The PDPA uses an optical system which is essentially the same as that of a typical Laser Doppler Velocimeter shown in figure 4. Droplets crossing the intersection of the two laser beams scatter light, producing a far field interference fringe pattern. The spacing of these fringes is inversely proportional to the droplet size. To obtain a measurement of this fringe spacing, the PDPA receiver uses three detectors, located at selected spacings. The three detectors produce threc Doppler burst signals which have a phase shift between them, figure 5. The phase shift is related to the droplet size using a linear relation illustrated in figure 6 . The phase shift between detectors 1 and 3 is sufficient to measure the droplet size. However, to increase the droplet size range while maintaining resolution of the measured phase shift, a third detector (detector 2) is used to identify phase shifts, between detectors 1 and 3, which are greater than 360 degrees. This also provides a second independent measurement of the droplet size which is used in the signal validation logic.

\section{Setup and Measurement Procedure}

The FSSP was mounted on a strut attached to the ceiling of the test section and positioned on the center 
line of the tunnel with the front of the flow straightening tube centered between the pair of heated windows. The PDPA transmitter and receiver were mounted on a pair of support columns attached to a common metal plate laying on the floor under the test section. The metal plate locked the transmitter and receiver together providing a stable alignment and permitted the alignment of the PDPA sample area with the FSSP by moving both components as a system.

Figure 7 illustrates the relative position of the PDPA sample area, the PMS sample areas, and the PMS instrument canister. The PDPA was mounted such that its sample area was positioned on the center line of the FSSP and one centimeter in front of the flow straightening tube. This placed the PDPA sample area $12 \mathrm{~cm}$ upstream of the FSSP sample area. The front dome of the FSSP canister was $26 \mathrm{~cm}$ downstream of the PDPA sample area. The OAP was mounted such that the distance from the instrument canister to the PDPA sample area and the distance between the OAP and PDPA sample area was the same as with the FSSP.

For each set of nozzles, measurements were taken it two steps. FSSP and PDPA measurements were taken for all nozzle test points. Then, the OAP was installed and all test points were repeated. Instrument measurements were started simultaneously after the spray nozzle pressures were set and stable. The sample time of the PMS and PDPA were not matched because the instrument's droplet sampling rates differ substantially. The PMS instruments sampled the cloud for a fixed time period. The FSSP sampled for 10 seconds and the OAP sampled for 40 seconds. The OAP's sample time was longer to compensate for the lower number densities of the large droplets in the tail of the distributions. The PDPA was set up to sample until it had processed 20,000 valid counts. The PDPA sample times varied from 9 to 60 seconds. In order to evaluate the repeatability of the cloud, the PDPA droplet size range was held constant for both the FSSP and OAP measurements.

An initial test was conducted at several tunnel velocities from $25 \mathrm{~m} / \mathrm{s}$ to $90 \mathrm{~m} / \mathrm{s}$ to investigate velocity effects on droplet sizing. All other tests were conducted at a velocity of $60 \mathrm{~m} / \mathrm{s}$ and a tunnel air temperature of $7^{\circ} \mathrm{C}$.

\section{$\underline{\text { Results and Discussion }}$}

Figure 8 shows the results of an evaluation of the velocity effect on droplet sizing for the PDPA and FSSP. Data were taken at five velocities from $25 \mathrm{~m} / \mathrm{s}$ to $90 \mathrm{~m} / \mathrm{s}$ and MVDs of 10, 20, and 32 microns. There appears to be no velocity effect over this range of drop sizes and velocities. There is, however, greater data scatter for measurements at both $25 \mathrm{~m} / \mathrm{s}$ and $90 \mathrm{~m} / \mathrm{s}$. The 32 micron points fall below the 1:1 line because the droplet size distribution exceeded the range of the FSSP causing the FSSP to undersize the MVD of the cloud. The spread in the 45,60 , and $75 \mathrm{~m} / \mathrm{s}$ data points is an indication of the combination of the instrument and cloud repeatability which is approximately 3 microns.

Figure 9 presents the MVD comparisons between the PDPA and the FSSP for the four nozzle sets tested. Between 10 and 20 microns the data is clustered in a 3 micron band about the line of perfect agreement. Above 20 microns the grouping falls below the line of agreement. Furthermore, the Standard and Mod1 nozzle types deviate from the 1:1 line at different MVDs. The Mod1 nozzles coincide with the line up to 18 microns and the Standard nozzles coincide with the line up to 22 microns. This difference may result from differences in the shape of the distribution produced by the two nozzle types. The trend indicated by this comparison could be caused by either the FSSP undersizing or the PDPA oversizing the MVD. The OAP distribution is required to resolve this question.

Figure 10 presents MVD comparison data between the PDPA and PMS (combined droplet size distribution from the FSSP and OAP) instruments. As a result of adding the OAP distributions to the FSSP distributions the agreement between the PDPA and PMS is extended up to 30 microns. However above 30 microns, the agreement quickly deteriorates. The average of the two PDPA measurements for each PMS measurement is represented by the symbol and the ends of the horizontal line through the symbols represents the two PDPA MVDs. Although most of the PDPA data indicated good cloud repeatability, a series of IRT Mod1 data from 20 to 40 microns suffers from poor cloud repeatability as indicated by the long horizontal lines through the symbols. This data exhibits differences of 4 to 10 microns between the two PDPA MVDs. The validity of the PMS MVDs for this series of data is doubtful because the poor repeatability indicates that the OAP and FSSP were measuring two different clouds. The fact that the cloud did not repeat may be the reason that this series of data are displaced from the 1:1 line and the rest of the comparison data. Above 30 microns, the data imply that the PDPA measurements have approached a maximum as the PMS continues to increase.

By comparing figures 9 and 10 it is evident that the trends presented in figure 9 results from the FSSP under estimating the actual MVD because the largest droplets 
in the distributions exceeded the measurement range of the FSSP. Furthermore, the difference between at what MVD the Mod1 and Standard nozzle measurements begin to deviate from agreement suggests that the limit of a valid MVD from the FSSP is dependent on the distribution shape.

The Mod1 and Standard nozzles have relatively narrow size distributions. For droplet size distributions wider than the IRT nozzles, the maximum valid MVD from the FSSP could be much smaller than the 18 microns indicated by this data. Without the additional data supplied by the OAP, it is a difficult task to determine if the FSSP's MVD is valid.

Figures 11, 12, 13, and 14 are typical drop size distributions from the FSSP, OAP, and PDPA. Tables 1, 2, 3, and 4 list the MVD, total number density, and total liquid water content (LWC) for these four distributions. The first two size bins of the OAP distributions have been omitted. For each figure only one PDPA distribution is presented to improve the figure clarity.

Figure 11(a) shows that for a 13 micron MVD there is a large difference between the FSSP and PDPA number density distribution below 10 microns. The first three bins of the FSSP have significantly higher counts then the equivalent bins for the PDPA. The FSSP and PDPA distributions have good agreement above 10 microns.

The difference between the PDPA and FSSP at small drop sizes may be caused by frozen droplets. In the NASA Icing Research Tunnel, droplet freeze-out was found to be significant at high air pressures and low water flow rates. ${ }^{7}$ The FSSP would undersize a frozen droplet because of the reduction in scattered light intensity. However, the PDPA would probably reject these droplets because surface defects, internal air bubbles, and internal crystalline structures would cause large differences between the two independent phase measurements. Although the difference in number density for small drop sizes is large, the effect on the MVD is only one micron because the volume contribution of the small droplets to the total volume is small. Figure 11(b) shows that only the first FSSP bin has significantly higher LWC than the equivalent PDPA LWC. Above 6.5 microns the agreement between the two distributions improves. For this case, the FSSP and PDPA agree within one micron as shown in table 1.

The scattering of data points evident at the end of the number density versus droplet size distribution is due to low counts in the last few size bins of the distribution.
The two horizontal groupings of data at the end of the PDPA number density distribution represent one and two counts per bin. This scattering of data is also evident in the FSSP distribution.

The magnitude of the OAP distribution is higher than expected. Typically the OAP would have no counts for this condition. ${ }^{8}$ These counts are believed to be caused by frost shedding from the walls of the tunnel and small water leaks from the tunnel spray bars. These nonspray particles prevailed despite repeated attempts to eliminate them.

Figure 12 presents a slightly larger MVD of 18 microns. This figure is similar to figure 11 containing the same difference between the PDPA and FSSP below 10 microns and agreement from 10 to 47 microns. The OAP distribution in this figure is slightly more ordered however the count levels are still higher than expected. The counts for the OAP distribution, after omitting the first two size bins, are 517 raw counts and 1088 corrected counts for a 40 second sample.

Figure 13 represents the typical distributions for a cloud with a 30 micron MVD. This figure presents several changes from figures 11 and 12 .

For this condition counts in the OAP increased. The raw counts are 5929 and the corrected counts are 21,243 after omitting the first two size bins. The improved statistics result in a smooth distribution over the OAP's droplet size range out to 300 microns.

Figure 13(b) shows that the agreement between the PDPA and FSSP has deteriorated. The FSSP LWC distribution is significantly lower than the PDPA distribution and has become distorted. The LWC distribution has an uncustomary concave curve from 9.5 microns to a peak at 24.5 microns. This distorted FSSP distribution had not existed in previous measurements with this instrument conducted in the NASA Icing Research Tunnel. ${ }^{\text {? }}$

In figure 13 the PDPA's size distribution ends at 116.4 microns whereas the OAP's size distribution continues out to 300 microns. Table 5 lists the PDPA counts per bin for the distribution presented in figure 13 . The counts per bin drops below 10 above 65 microns and the counts are less than 2 above 82 microns. From 82 microns to 122 microns there are only 8 total counts. The PDPA size range for this measurement appears to be satisfactory with the distribution ending well before 122 microns. However based on the OAP distribution which 
continues out to 300 microns, the PDPA measurement is not adequately characterizing the distribution.

The PDPA distribution is not limited by the measurement range, but is limited by poor statistics in the large drop size bins, even though the total sample size was 38,059 corrected counts. As shown in table 5, counts per bin at the end of the PDPA's distribution are zeros and ones. The OAP's ability to characterize the distribution is superior to the PDPA's because, considering the relative sample areas, bin widths, and sampling times, the PDPA would record one count and the OAP 7000 counts. The OAP's number density distribution was used to calculate the counts the PDPA would register if the PDPA measured the same distribution as the OAP for bins 26 through 50 (listed in table 5 as calculated counts). Above 82 microns the calculated counts are below 2 counts and are fractions of a count above 95 microns which is consistent with the PDPA measurement. A valid MVD requires that there is good statistics in all of the size bins that affect the calculated MVD, especially size bins at the end of the distribution.

The PDPA's configuration could have been changed for the OAP tests to more closely match the OAP's measurement range, but was kept constant so that the cloud repeatability could be determined. The PDPA size range would have been approximately 8.5 to 300 microns. This range may have been sufficient to accurately determine the MVDs above 30 microns. If not, the two PDPA measurements would need to be combined in a similar manner as the PMS measurements. These two PDPA ranges would have a large overlap region of 8.5 to 60 microns or greater.

The PDPA's measurement range was defined during testing to best measure the droplet distribution. Typically an initially range is used to sample the cloud. The suitability of this measurement range is evaluated based on 1) the largest few bins have zero counts, 2) the ratio of the maximum drop size of the range to the MVD is greater than 4 , and 3 ) the shape of the number density and volume distributions indicates that the distribution is ending before the limits of the range. During testing, based on these criteria, it appeared that the PDPA's measurement range was properly defined. However, only through comparison with the OAP distribution did the deficiency in the PDPA's measurement range become apparent. In the PDPA, as well as other instruments, criteria are needed to determine whether the measurement range is sufficient to produce a valid MVD.
The combination of the failure of the PDPA to measure the large drop sizes and the overall reduction of the FSSP's volume distribution causes the large differences between the PMS and PDPA MVDs above 30 microns. For these conditions the PMS MVDs are oversized and the PDPA MVDs are undersized.

Figure 14 presents typical distributions for a 47 micron MVD icing cloud. This figure shows trends similar to the trends shown in figure 13. The PDPA and OAP appear to be measuring different droplet size ranges of the same distribution. The FSSP's distribution is lower than the PDPA's distribution and has the same distortion as shown in figure 13 .

\section{Conclusions}

The comparison of the Phase Doppler Particle Analyzer, the Forward Scattering Spectrometer Probe, and Optical Array Probe over a large range of drop sizes has been presented. Comparison of number density and liquid water content distributions has demonstrated good overall agreement and has identified several specific areas where they differ.

A comparison of the droplet size measurements from the Phase Doppler Particle Analyzer and the Particle Measuring Systems, Forward Scattering Spectrometer Probe and Optical Array Probe show's gon! agreement for median volume diameters between 10 and 30 microns.

For most icing cloud conditions, the drop size distribution of the Phase Doppler Particle Analyzer and Forward Scattering Spectrometer Probe below 10 microns differ significantly. This difference has a small effect on median volume diameters below 15 microns and no effect on median volume diameters above 15 microns.

For icing cloud conditions with median volume diameters above 30 microns, the Particle Measuring Systems median volume diameters are oversized because magnitude of the volume distribution from the Forward Scattering Spectrometer Probe decreases relative to the Optical Array Probe. The Phase Doppler Particle Analyzer undersizes MVDs above 30 microns because for the configuration used, it failed to detect the large drop size end of the distribution because of insufficient sampling statistics. These effects combine to cause large differences between the median volume diameters above 30 microns produced by these two droplet measurement systems. 


\section{Recommendations}

This test revealed specific areas where the PDPA and the PMS instruments disagree. Further comparison should be conducted to investigate these areas. A comparison between the PDPA and FSSP should be conducted with an ambient temperature droplet cloud to determine if droplet freeze-out causes the difference between these two instruments below 10 microns. For cloud conditions above 30 micron MVDs, a comparison between the PDPA and OAP should be conducted with the PDPA configured so that the upper limit of the PDPA's size range matches the OAP's and the counts at the end of the distribution are statistically significant. This test should be repeated using different types of spray nozzles to determine the effect of distribution shape on the comparison of these instruments.

\section{References}

1. Rudoff, R.C., Smith, J.N., and Bachalo, W.D., "Devclopment of a Phase Doppler Based Probe for Icing Cloud Droplet Characterization," AIAA 28th Aerospace Sciences Meeting, Paper no. 90-0667, 1990.

2. Tenison, G. V., "Development of a New Subsonic Icing Wind Tunnel," AIAA 27th Acrospace Sciences Meeting, Paper no. 89-0773, 1989.

3. Forward Scattering Spectrometer Probe, PMS Model FSSP-100, Operating and Service Manual, Particle Measuring Systems, Inc., Boulder, CO, 1984.

4. Optical Array Cloud Droplet Spectrometer Probe, PMS Model OAP-200X, Operating Manual, Particle Measuring Systems, Inc., Boulder, CO.

5. Baumgardner, D., "Corrections for the Response Times of Particle Measuring Probes," 6th Symposium Meteorological Observations and Instrumentation, New Orleans, La, 1987, pp 148-151.

6. Bachalo, W. D. and Houser, M. J., "Development of the Phase Doppler Spray Analyzer for Liquid Drop Size and Velocity Characterizations," AIAA 20th Joint Propulsion Conference, Paper no. 84-1199, 1984.

7. Bachalo, W.D., and Houser, M.J., "Analysis and Testing of a New Method for Drop Size Measurement Using Laser Light Scatter Interferometry," NASA CR 174636, August 1984.
8. Ide, R.F., "Liquid Water Content and Droplet Size Calibration of the NASA Lewis Icing Research Tunnel," AIAA 28th Aerospace Science Meeting, Paper no. 90-0669, 1990.

9. Hovenac, E.A., and Ide, R.F., "Performance of the Forward Scattering Spectrometer Probe in NASA's Icing Research Tunnel," AIAA 27th Aerospace Science Meeting, Paper no. 89-0769, NASA TM 101381, 1989. 
Table 1. Numerical Data for Distributions in figure 11.

\begin{tabular}{|l|c|c|c|}
\hline INSTRUMENT & MVD & $\begin{array}{c}\text { NUMBER } \\
\text { DENSITY } \\
\text { um } / \mathrm{cc}\end{array}$ & LWC \\
\hline FSSP & 12.7 & 338 & 0.135 \\
OAP & 181.4 & 0.0121 & 0.0127 \\
PDPA with FSSP & 12.2 & 151 & 0.0752 \\
PDPA with OAP* & 11.7 & 174 & 0.0852 \\
PMS & 13.3 & 338 & 0.148 \\
\hline Nozzle Condition: Pair $=80$ psig DeltaP $=40 \mathrm{psi}$ \\
* Distribution not shown to improve figure clarity. \\
\hline
\end{tabular}

Table 3. Numerical Data for Distributions in figure 13.

\begin{tabular}{|l|c|c|c|}
\hline INSTRUMENT & MVD & $\begin{array}{c}\text { NUMBER } \\
\text { DENSITY } \\
\mathrm{n} / \mathrm{cc}\end{array}$ & $\mathrm{LW} / \mathrm{m} / \mathrm{m} 3$ \\
\hline FSSP & 23.8 & 207 & 0.259 \\
OAP & 62.6 & 7.19 & 0.18 \\
PDPA with FSSP & 29.1 & 241 & 0.654 \\
PDPA with OAP* & 30.6 & 233 & 0.704 \\
PMS & 30.5 & 207.4 & 0.388 \\
\hline \multicolumn{3}{|c|}{ Pair $=60$ psig DeltaP $=247 \mathrm{psi}$} \\
Nozzle Condition: \\
* Distribution not shown to improve figure clarity. \\
\hline
\end{tabular}

Table 2. Numerical Data for Distributions in figure 12.

\begin{tabular}{|l|c|c|c|}
\hline INSTRUMENT & MVD & $\begin{array}{c}\text { NUMBER } \\
\text { DENSITY } \\
\text { um/cc }\end{array}$ & LWC \\
\hline FSSP $/ \mathrm{m3}$ \\
OAP & 18.1 & 457 & 0.44 \\
PDPA with FSSP & 182.2 & 1.04 & 0.0391 \\
PDPA with OAP* & 16.9 & 345 & 0.317 \\
PMS & 16.9 & 296 & 0.299 \\
\hline Nozzle Condition: Pair $=80$ psig DeltaP $=200 \mathrm{psi}$ \\
* Distribution not shown to improve figure clarity. \\
\hline
\end{tabular}

Table 4. Numerical Data for Distributions in figure 14.

\begin{tabular}{|c|c|c|c|}
\hline INSTRUMENT & $\begin{array}{l}\text { MVD } \\
\text { um } \\
\end{array}$ & $\begin{array}{c}\text { NUMBER } \\
\text { DENSITY } \\
n / c c\end{array}$ & $\begin{array}{c}\text { LWC } \\
\mathrm{gm} / \mathrm{m} 3\end{array}$ \\
\hline FSSP & 24.1 & 103 & 0.124 \\
\hline OAP & 72.7 & 4.44 & 0.151 \\
\hline PDPA with FSSP & 33.6 & 86.2 & 0.337 \\
\hline PDPA with OAP* & 32.6 & 119 & 0.404 \\
\hline PMS & 47 & 103.3 & 0.248 \\
\hline
\end{tabular}


Table 5. PDPA corrected counts per bin for distribution in figure 13. Calculated counts based on converting the OAP number density distribution to equivalent PDPA counts.

\begin{tabular}{|c|c|c|c|c|c|c|c|c|}
\hline Bin & Diameter & $\begin{array}{c}\text { PDPA } \\
\text { Counts }\end{array}$ & $\begin{array}{c}\text { Calculated } \\
\text { Counts }\end{array}$ & & Bin & Diameter & $\begin{array}{c}\text { PDPA } \\
\text { Counts }\end{array}$ & $\begin{array}{c}\text { Calculated } \\
\text { Counts }\end{array}$ \\
\hline 1 & 4.6 & 6187 & - & & 26 & 64.1 & 11 & 6.17 \\
2 & 7.0 & 6055 & - & & 27 & 66.5 & 5 & 5.46 \\
3 & 9.4 & 6927 & - & & 28 & 68.9 & 3 & 4.86 \\
4 & 11.8 & 5553 & - & & 29 & 71.2 & 5 & 4.21 \\
5 & 14.1 & 4003 & - & & 30 & 73.6 & 3 & 3.65 \\
6 & 16.5 & 2765 & - & & 31 & 76.0 & 3 & 3.12 \\
7 & 18.9 & 1999 & - & & 32 & 78.4 & 3 & 2.62 \\
8 & 21.3 & 1233 & - & & 33 & 80.7 & 4 & 2.12 \\
9 & 23.7 & 914 & - & & 34 & 83.1 & 1 & 1.75 \\
10 & 26.0 & 639 & - & & 35 & 85.5 & 0 & 1.41 \\
11 & 28.4 & 480 & - & & 36 & 87.9 & 0 & 1.27 \\
12 & 30.8 & 321 & - & & 37 & 90.3 & 2 & 1.13 \\
13 & 33.2 & 235 & - & & 38 & 92.6 & 1 & 1.02 \\
14 & 35.5 & 183 & - & & 39 & 95.0 & 0 & 0.94 \\
15 & 37.9 & 117 & - & & 40 & 97.4 & 1 & 0.86 \\
16 & 40.3 & 94 & - & & 41 & 99.8 & 1 & 0.78 \\
17 & 42.7 & 87 & - & & 42 & 102.2 & 0 & 0.71 \\
18 & 45.1 & 69 & - & & 43 & 104.5 & 1 & 0.64 \\
19 & 47.4 & 31 & - & & 44 & 106.9 & 0 & 0.59 \\
20 & 49.8 & 25 & - & & 45 & 109.3 & 0 & 0.53 \\
21 & 52.2 & 23 & - & & 46 & 111.7 & 0 & 0.48 \\
22 & 54.6 & 20 & - & & 47 & 114.1 & 0 & 0.42 \\
23 & 57.0 & 25 & - & & 48 & 116.4 & 1 & 0.38 \\
24 & 59.3 & 18 & - & & 49 & 118.8 & 0 & 0.33 \\
25 & 61.7 & 11 & - & & 50 & 121.2 & 0 & 0.28 \\
\hline
\end{tabular}




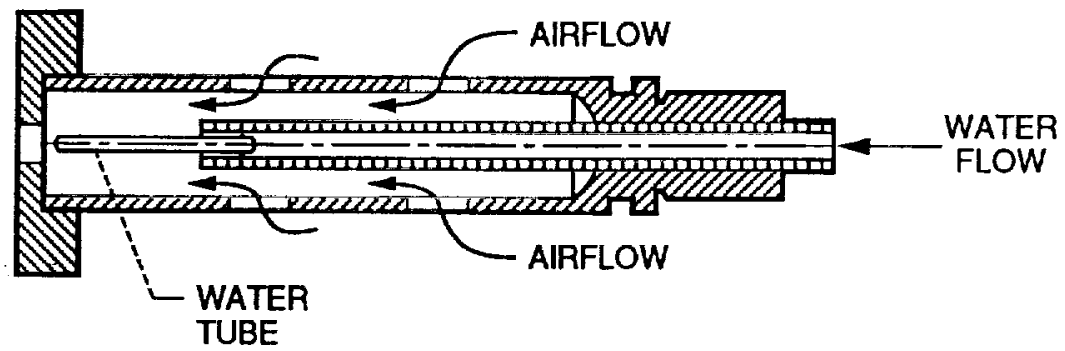

Figure 1. - NASA lcing Research Tunnel spray nozzle configuration.

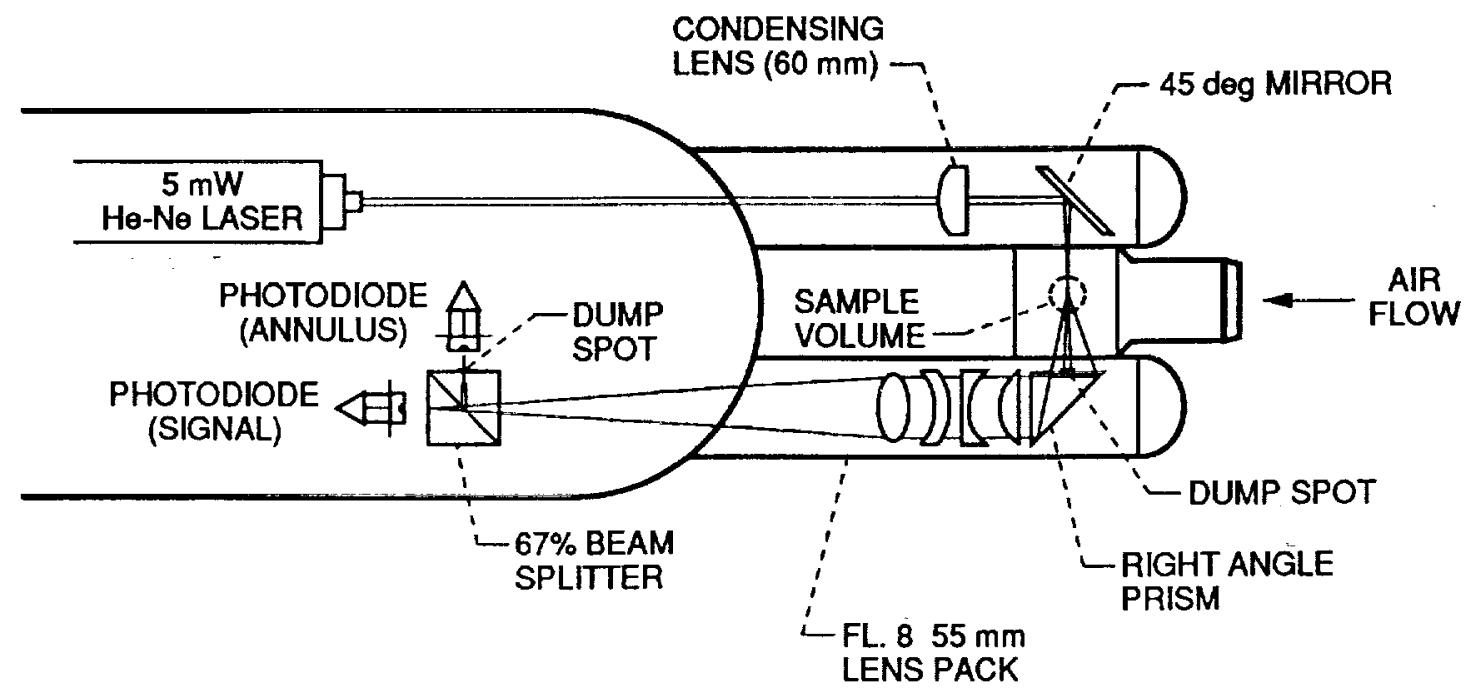

Figure 2. - Forward Scattering Spectrometer Probe optical configuration.

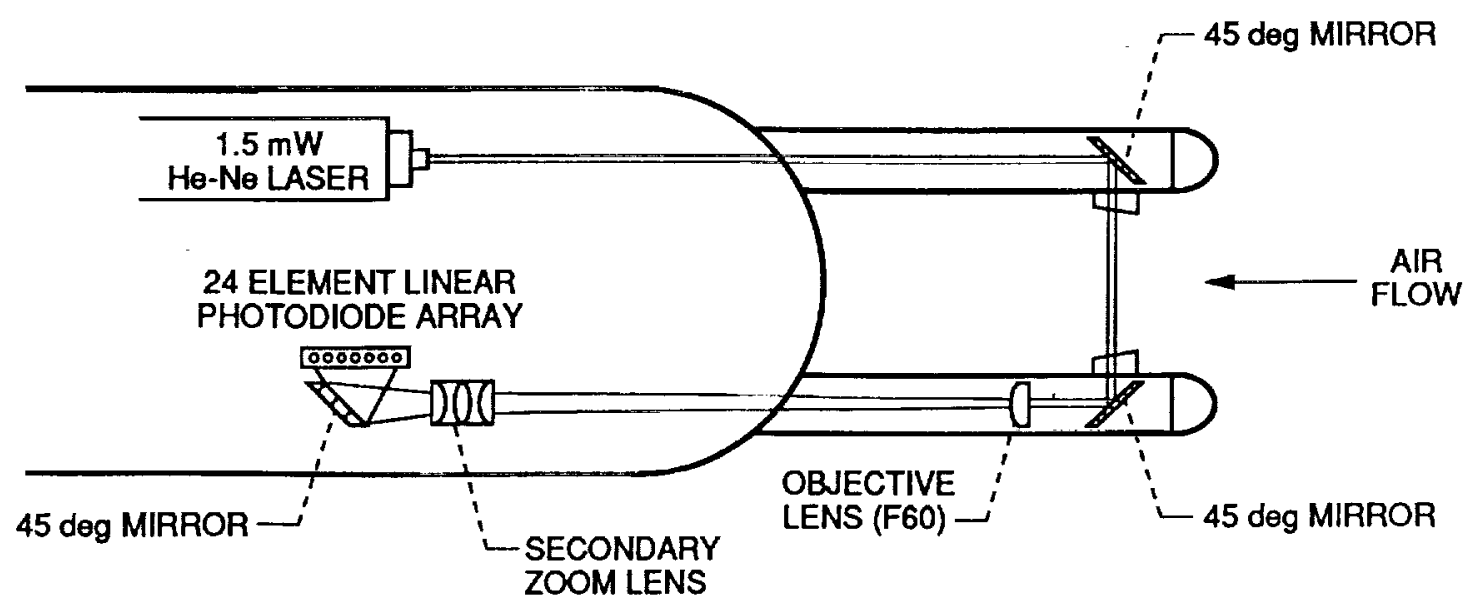

Figure 3. - Optical Array Probe optical configuration. 


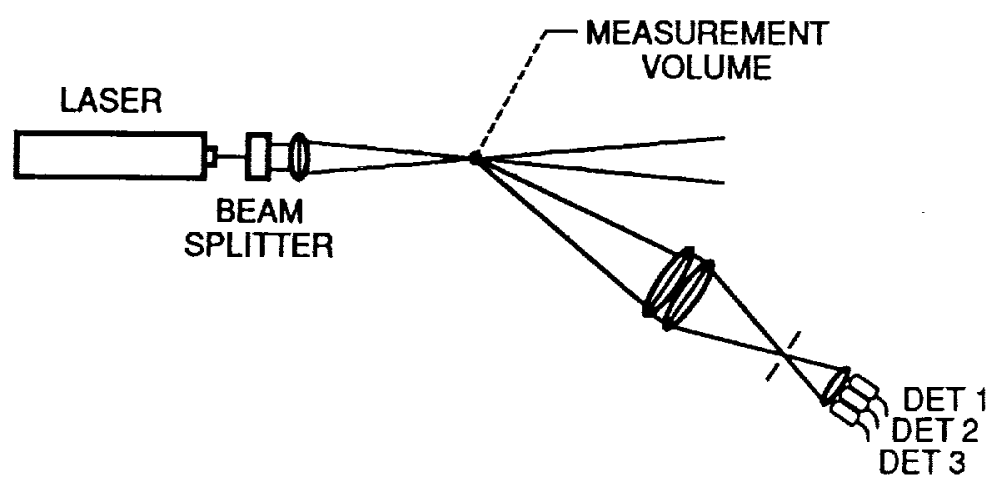

Figure 4. - Phase Doppler Particle Analyzer optical configuration.

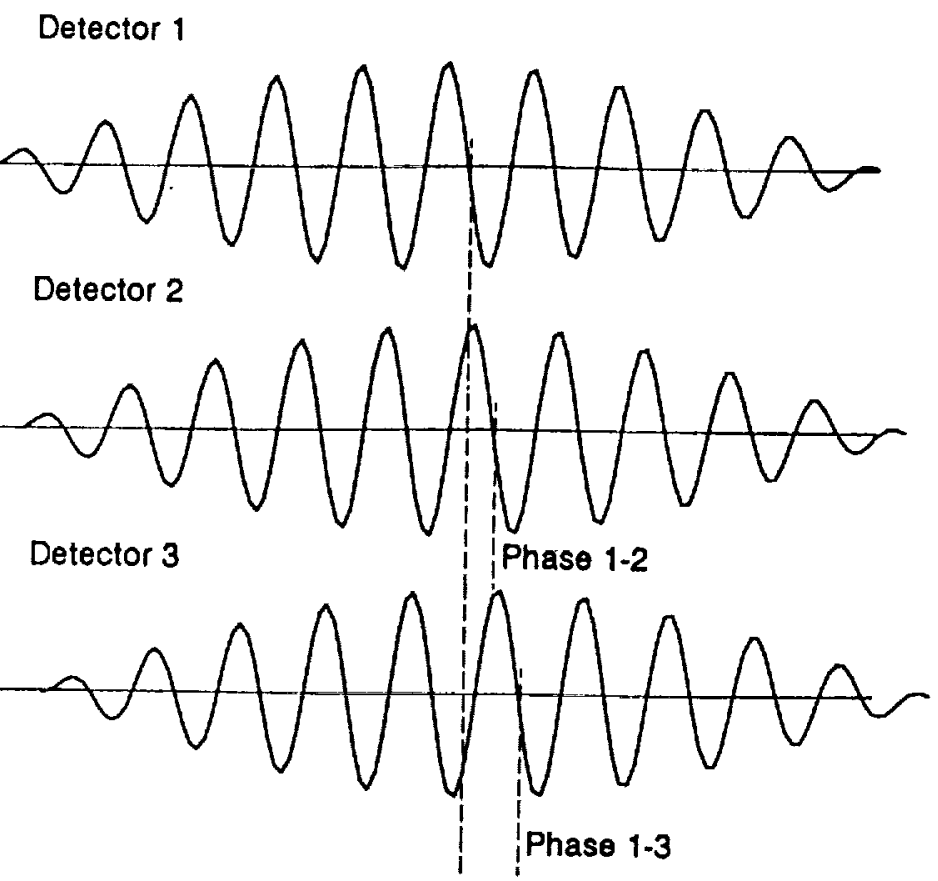

Figure 5. - PDPA filtered Doppler burst signals from the three signal detectors with the phase shift between signals illustrated. 


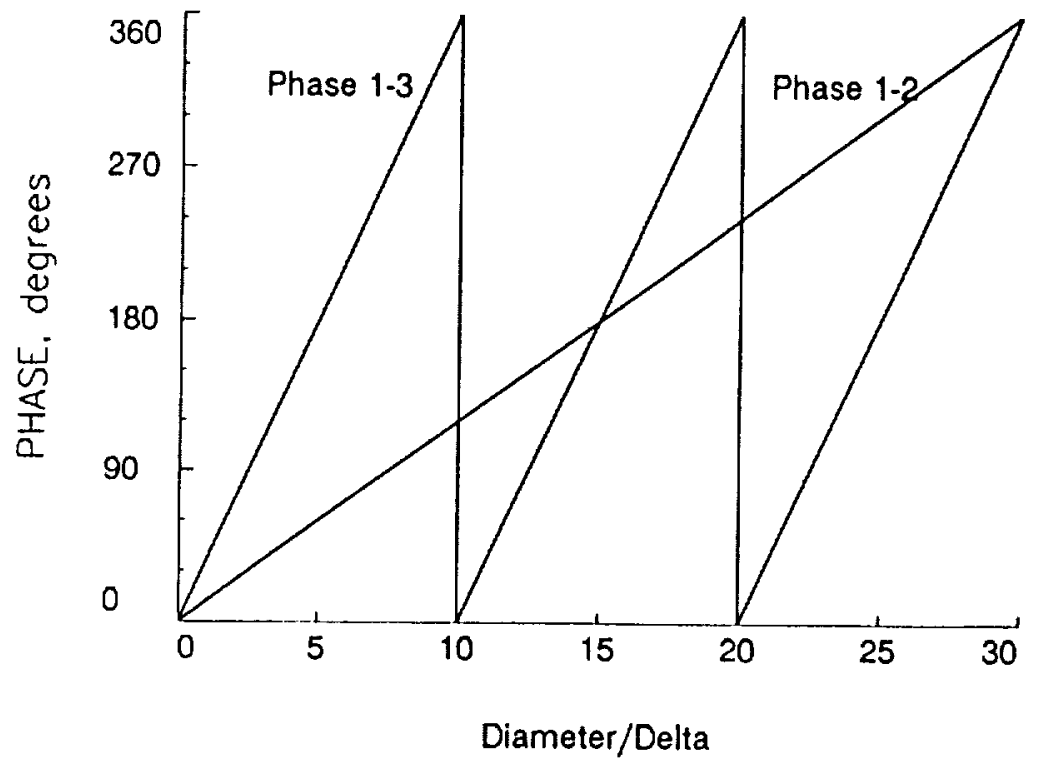

Figure 6. - PDPA instrument response curves.

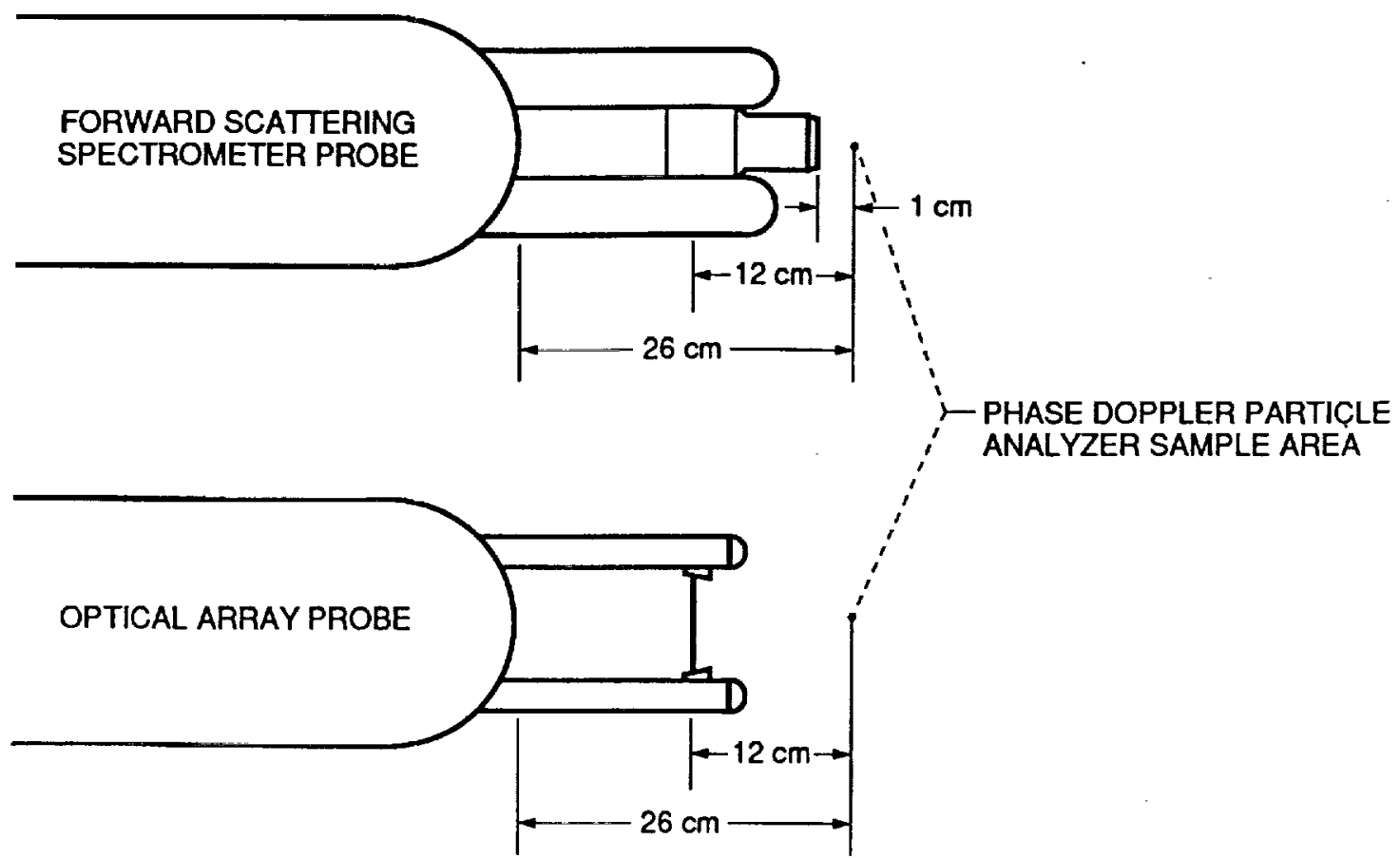

Figure 7. - Illustration of the relative position of the PDPA sample area to the FSSP and OAP. 


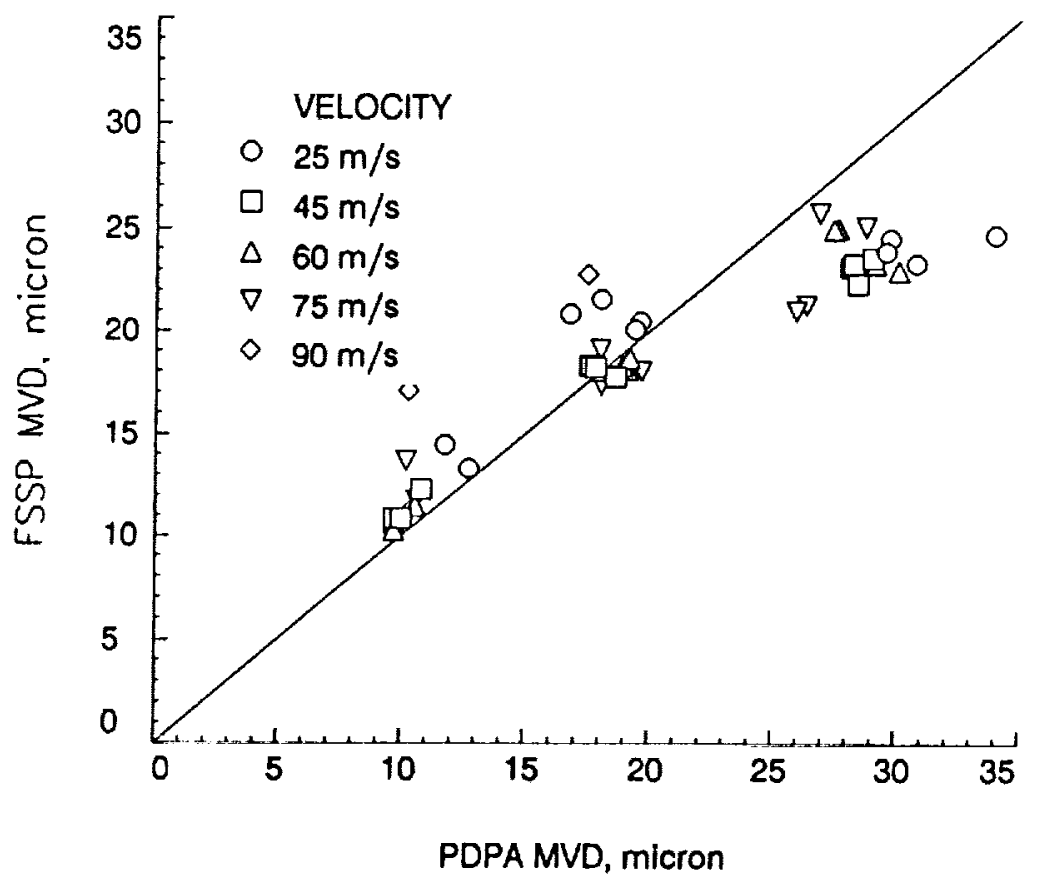

Figure 8. - Velocity effect on droplet sizing for the PDPA and FSSP. Three nominal median volume diameters; 10,20 , and 32 microns.

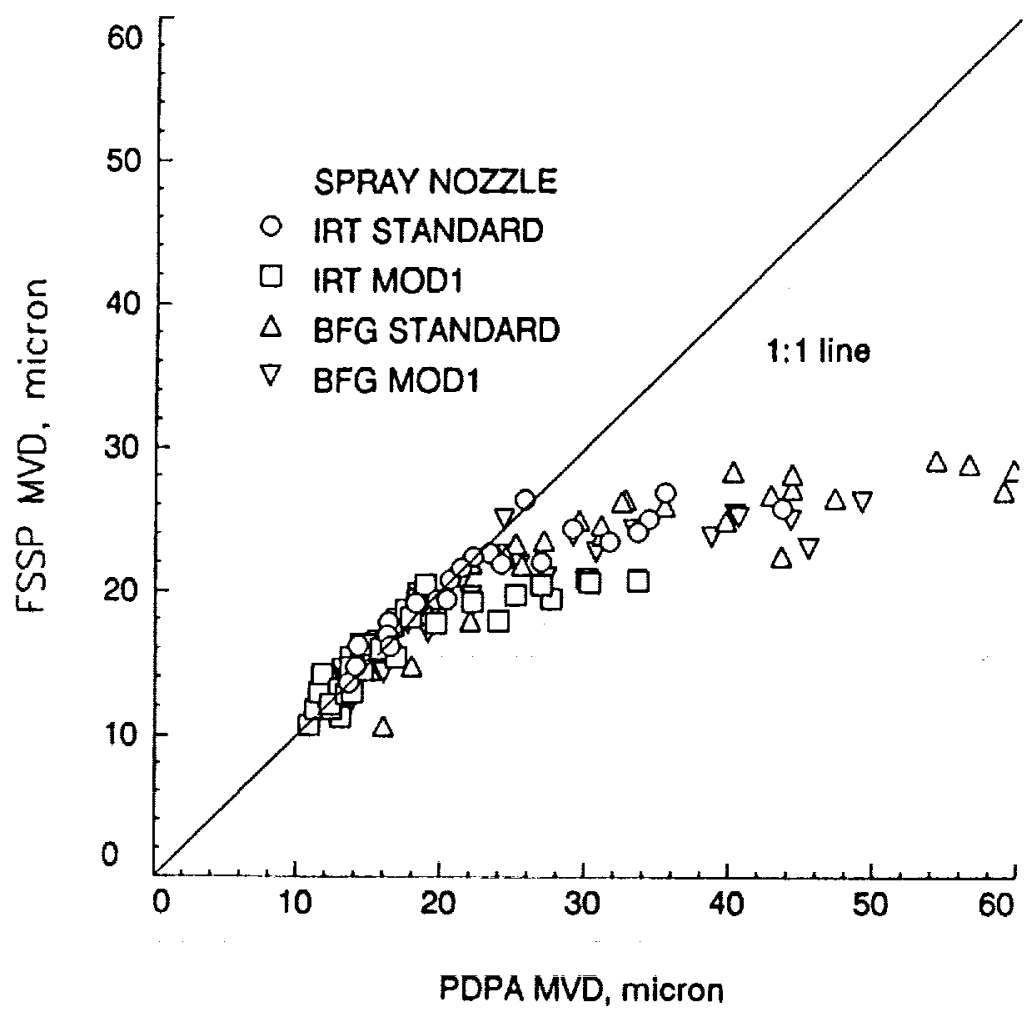

Figure 9. - Comparison of the MVDs from the PDPA and FSSP for the four spray nozzles tested. 


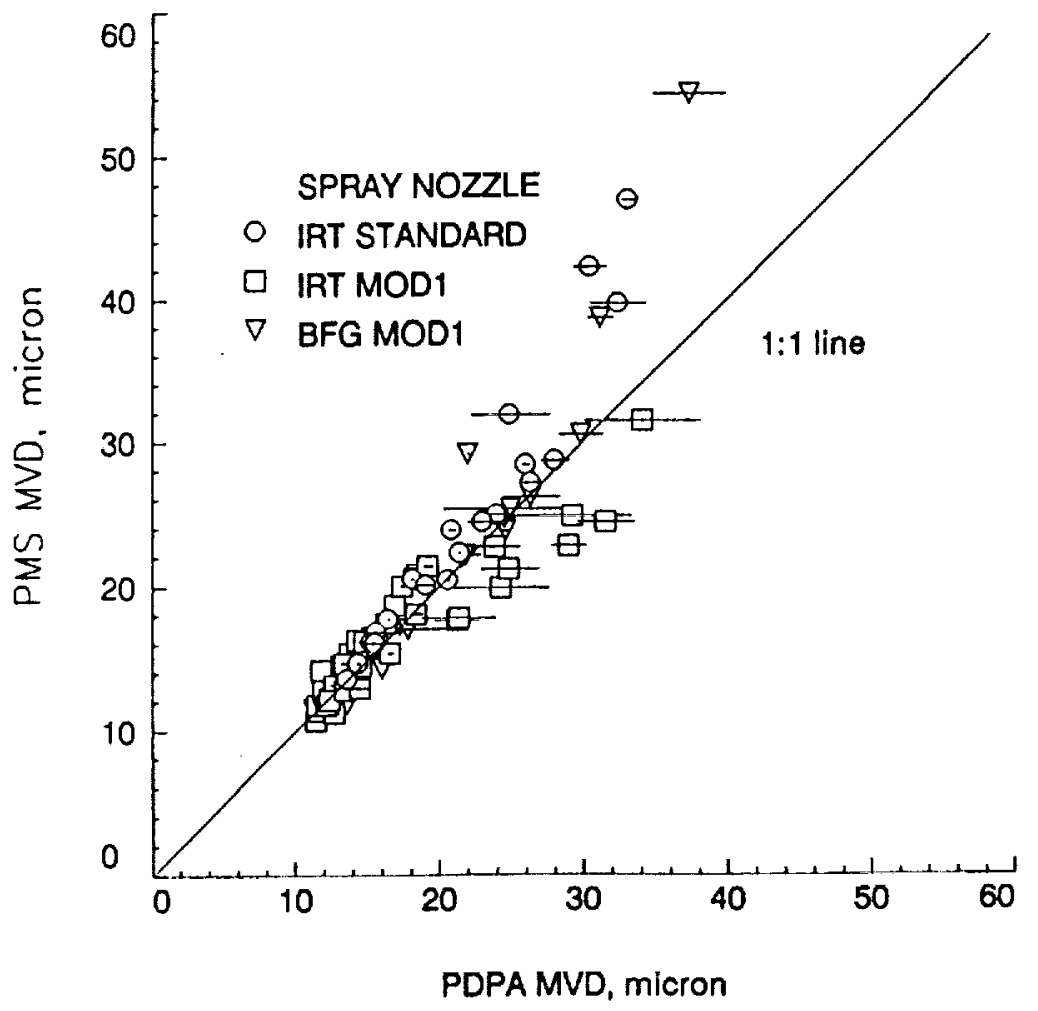

Figure 10. - Comparison of the MVDs from the PDPA and the PMS combined distribution. Limits of the horizontal bars represents the two PDPA MVDs and the symbol represents the average of the two PDPA MVDs. 


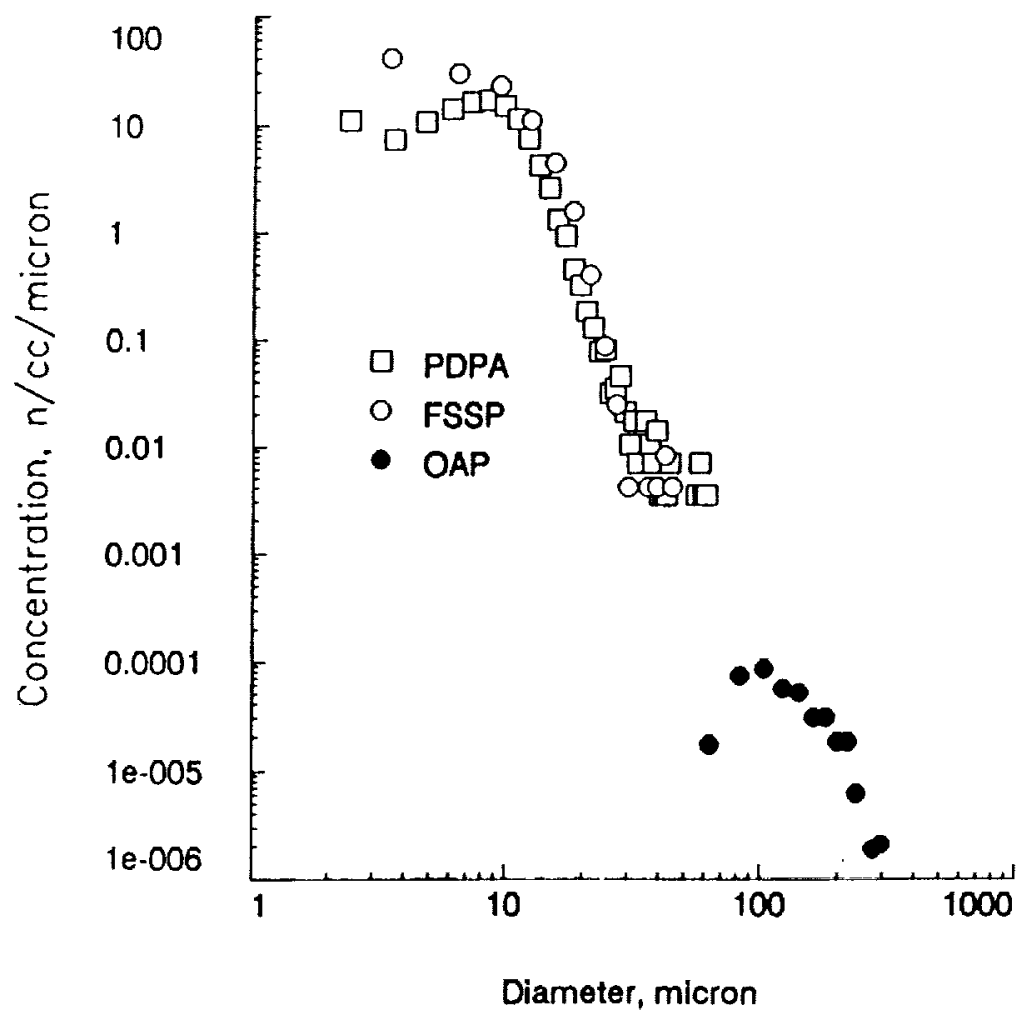

(a) Number density.

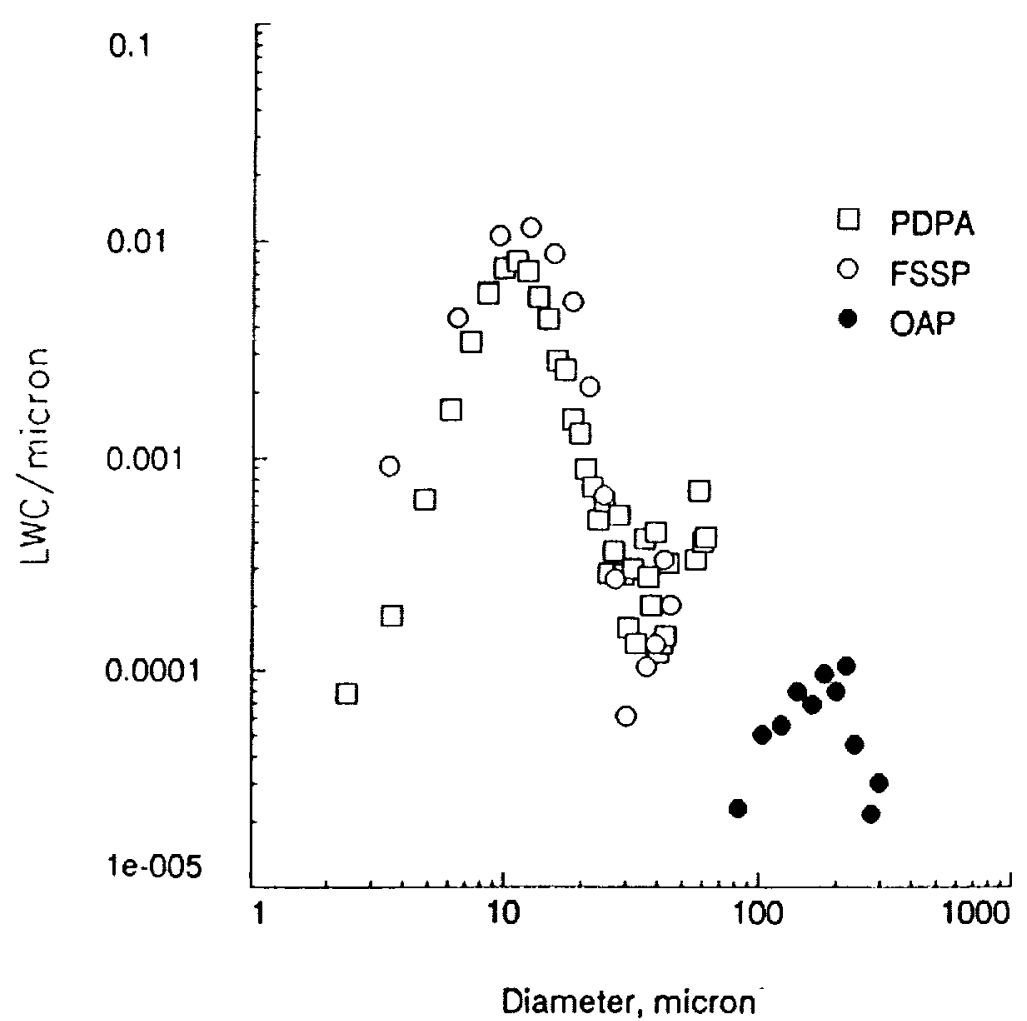

(b) Liquid water content.

Figure 11. - Distributions for a 13 micron cloud from the FSSP, OAP, and PDPA. 


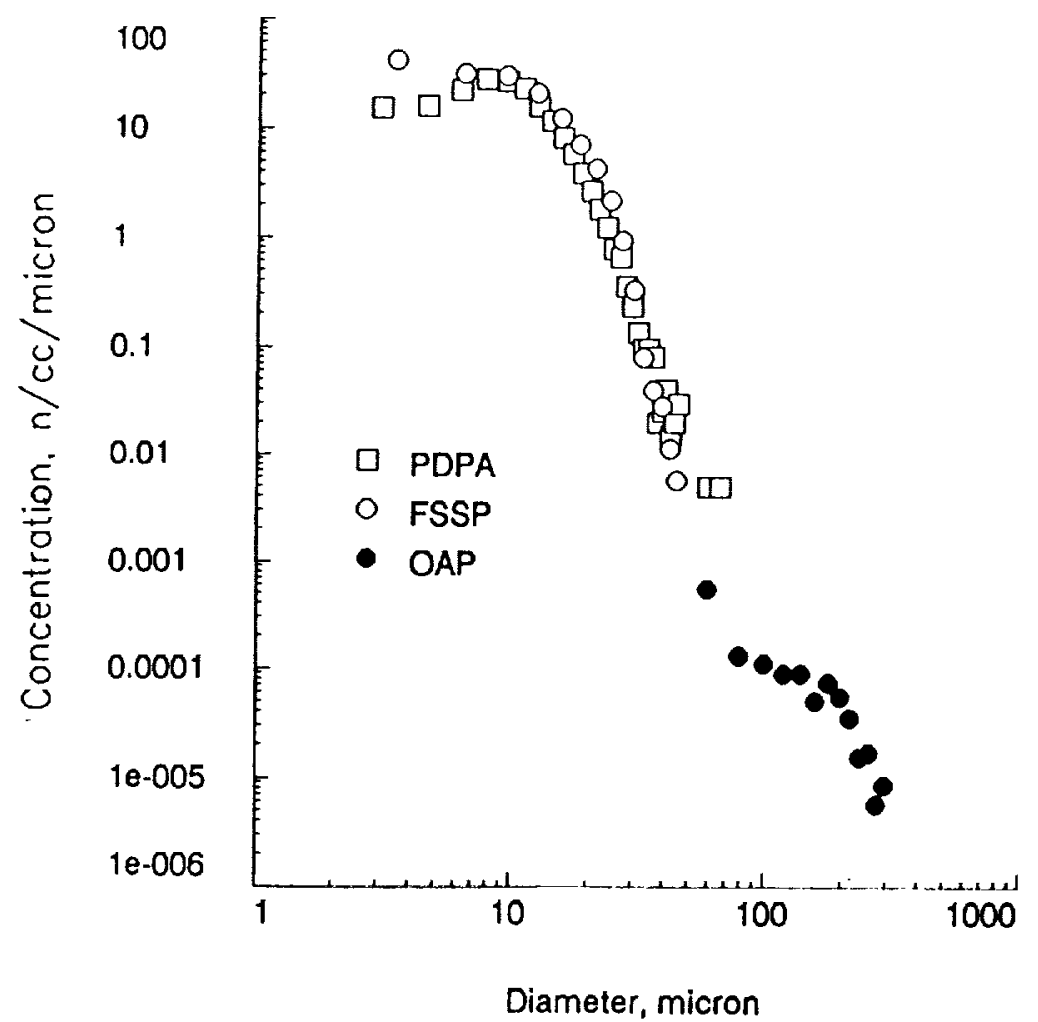

(a) Number density.

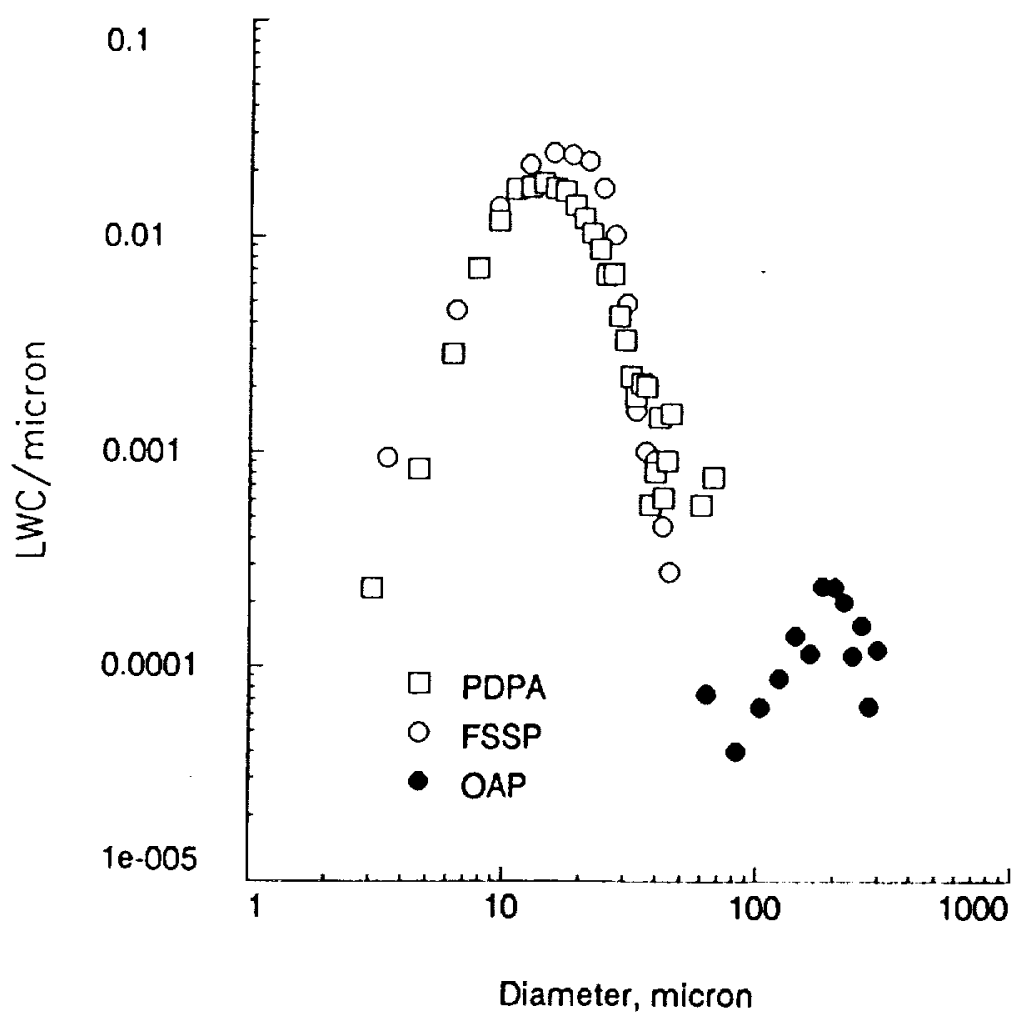

(b) Liquid water content.

Figure 12. - Distributions for a 18 micron cloud from the FSSP, OAP, and PDPA. 


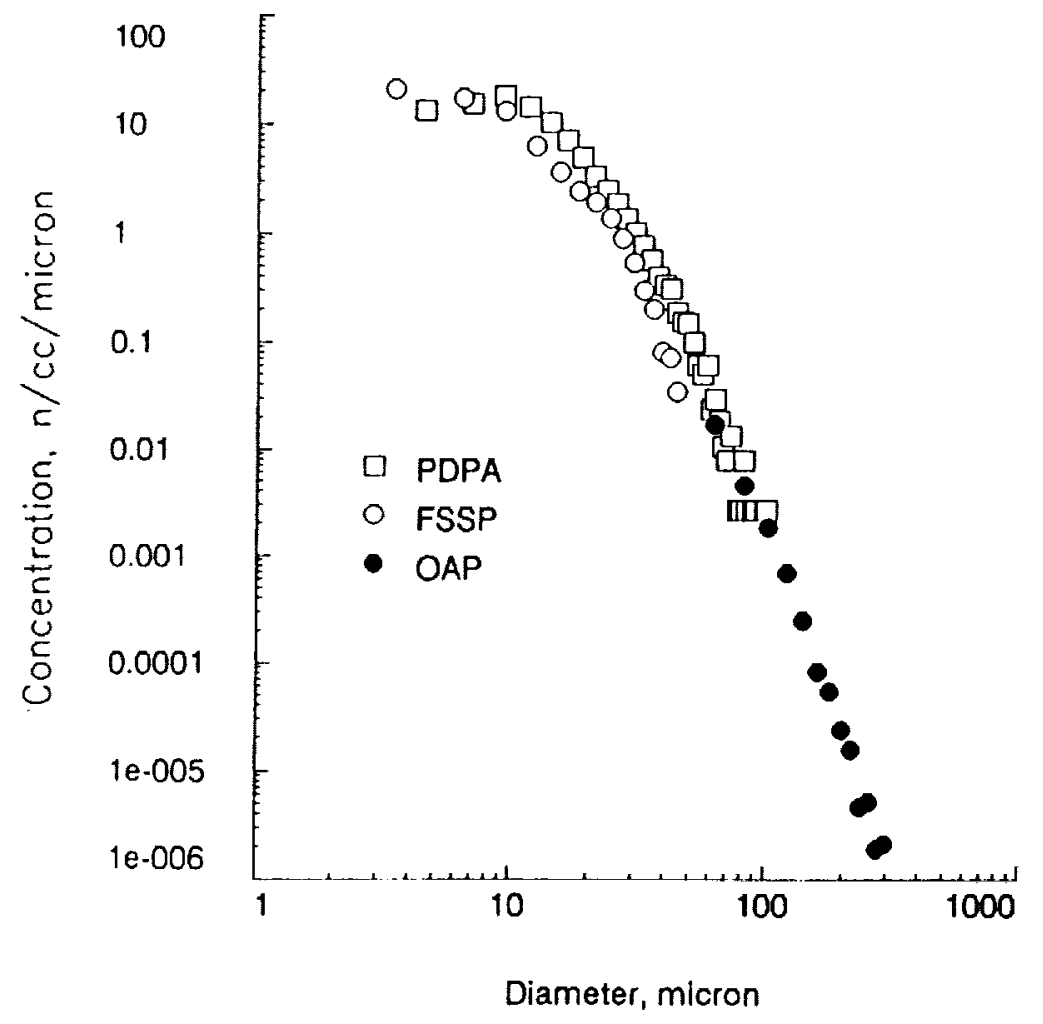

(a) Number density.

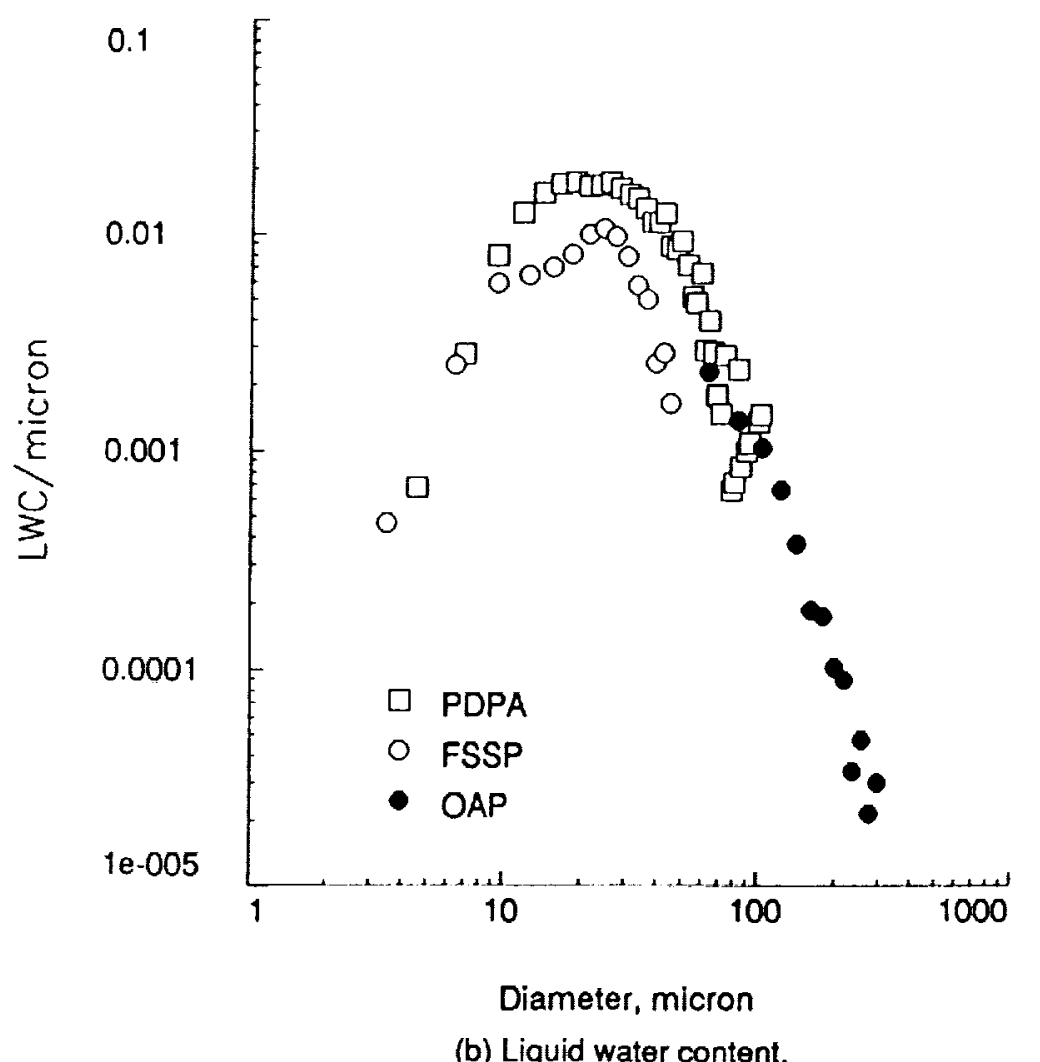

Figure 13. - Distributions for a 30 micron cloud from the FSSP, OAP, and PDPA. 


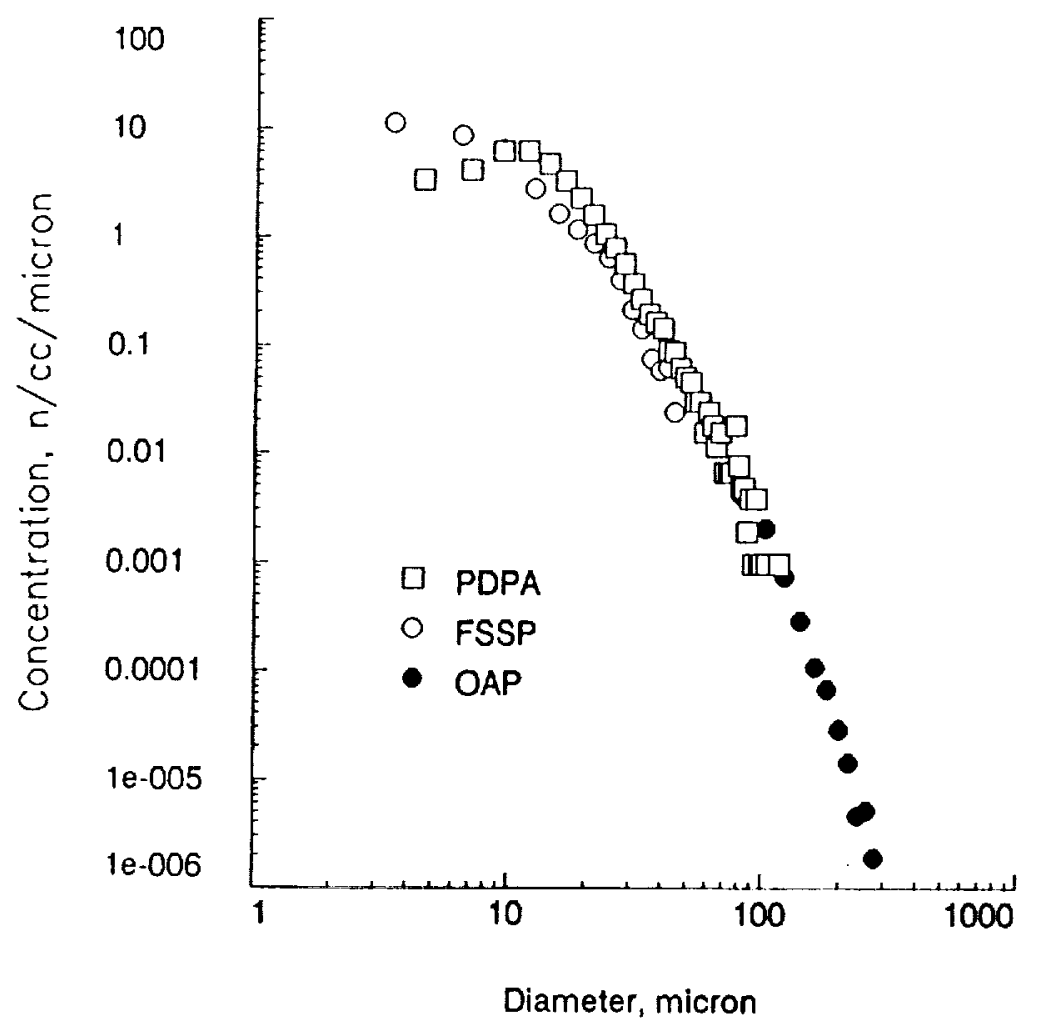

(a) Number density.

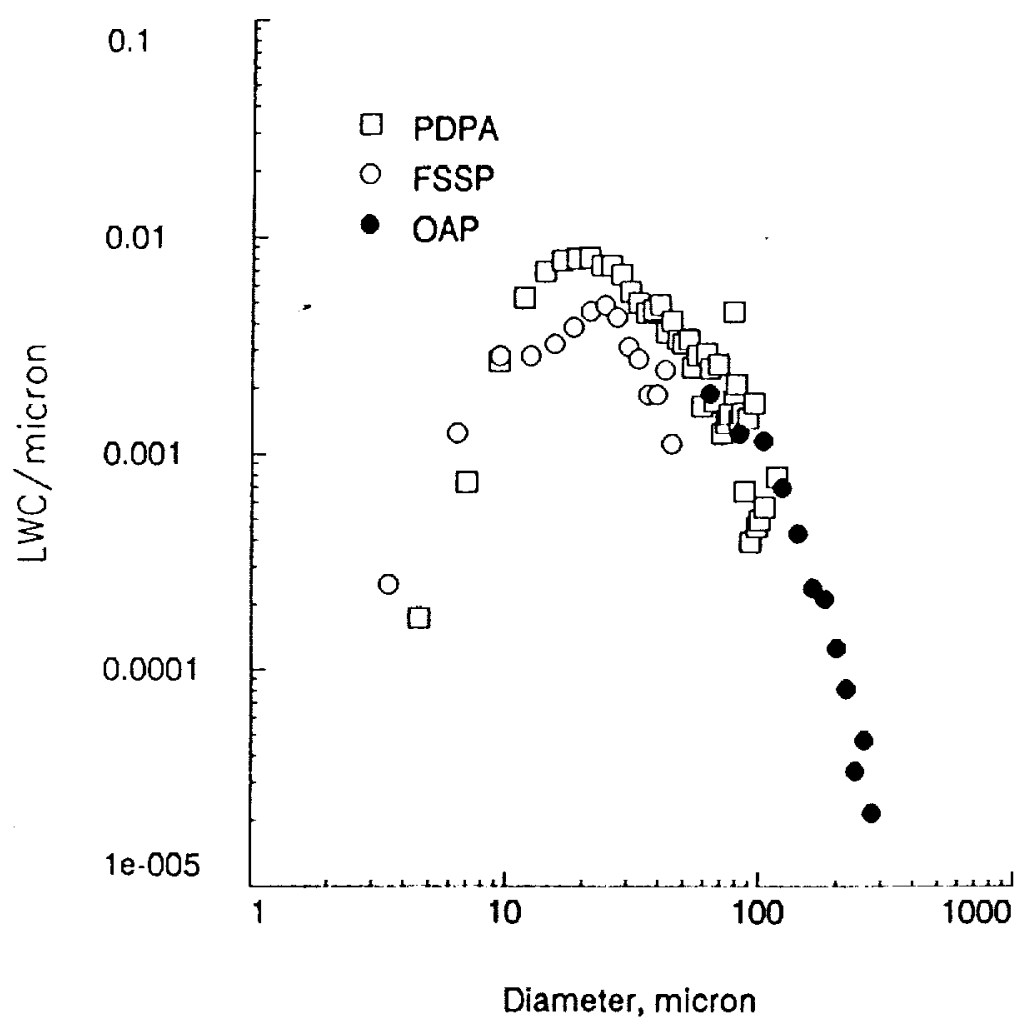

(b) Liquid water content.

Figure 14. - Distributions for a 47 micron cloud from the FSSP, OAP, and PDPA. 


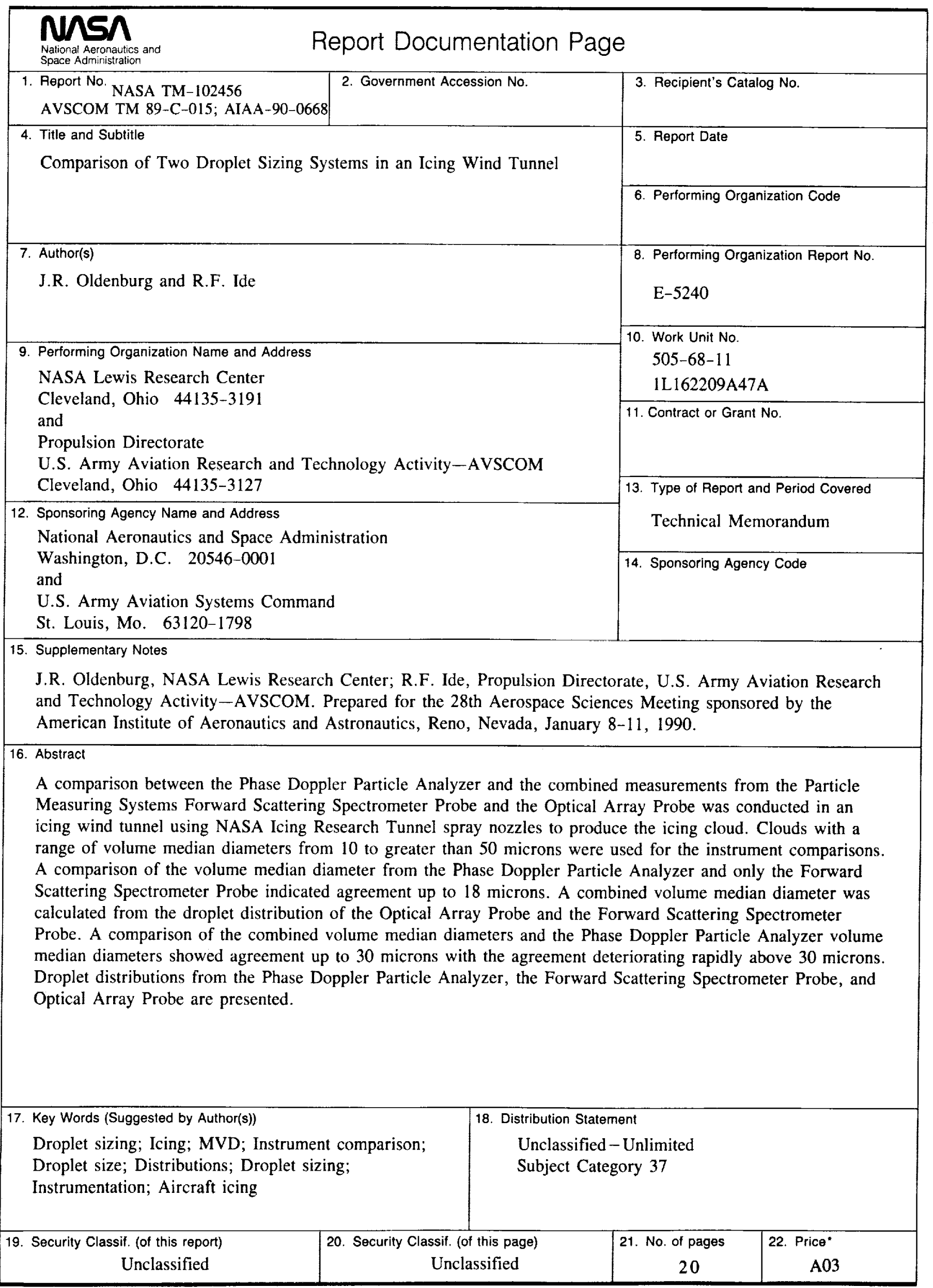

